This is the author's final, peer-reviewed manuscript as accepted for publication. The publisher-formatted version may be available through the publisher's web site or your institution's library.

\title{
Ultrasonic vibration-assisted pelleting for cellulosic biofuel manufacturing: investigation on power consumption
}

Qi Zhang, Pengfei Zhang, Zhijian Pei, Donghai Wang

\section{How to cite this manuscript}

If you make reference to this version of the manuscript, use the following information:

Zhang, Q., Zhang, P., Pei, Z., \& Wang, D. (2013). Ultrasonic vibration-assisted pelleting for cellulosic biofuel manufacturing: Investigation on power consumption. Retrieved from http://krex.ksu.edu

\section{Published Version Information}

Citation: Zhang, Q., Zhang, P., Pei, Z., \& Wang, D. (2013). Ultrasonic vibration-assisted pelleting for cellulosic biofuel manufacturing: Investigation on power consumption. Renewable Energy, 55, 175-181.

Copyright: (c) 2012 Elsevier Ltd.

Digital Object Identifier (DOI): doi:10.1016/j.renene.2012.12.015

Publisher's Link: http://www.sciencedirect.com/science/article/pii/S0960148112007793

This item was retrieved from the K-State Research Exchange (K-REx), the institutional repository of Kansas State University. K-REx is available at http://krex.ksu.edu 
Ultrasonic vibration-assisted pelleting for cellulosic biofuel manufacturing: investigation on power consumption

\section{Qi Zhang}

Department of Industrial and Manufacturing Systems Engineering, Kansas State University, 2037 Durland Hall, Manhattan, KS 66506, USA

Email: qizhang@ksu.edu

Pengfei Zhang (corresponding author)

Department of Industrial and Manufacturing Systems Engineering, Kansas State University, 2037 Durland Hall, Manhattan, KS 66506, USA

Email: pengfei@ksu.edu

Telephone: (01)785-532-3729

Fax: 785-532-3738

\section{Zhijian Pei}

Department of Industrial and Manufacturing Systems Engineering, Kansas State University, 2037 Durland Hall, Manhattan, KS 66506, USA

Email: zpei@ksu.edu

Telephone: (01)785-532-3436

Fax: 785-532-3738

\section{Donghai Wang}

Department of Biological and Agricultural Engineering, Kansas State University, 150 Seaton Hall, Manhattan, KS 66506, USA

Email: dwang@ksu.edu 


\section{ABSTRACT}

Cellulosic ethanol produced from cellulosic biomass is an alternative to petroleumbased transportation fuels. Raw cellulosic biomass has low density, causing high costs in their storage, transportation, and handling. Ultrasonic vibration-assisted (UV-A) pelleting can increase the density of cellulosic biomass. Effects of UV-A pelleting variables on pellet quality (density, durability, stability, and strength) and sugar yield have been reported. However, power consumption in UV-A pelleting has not been fully investigated. This paper presents an experimental investigation on power consumption in UV-A pelleting of wheat straw. Effects of input variables (biomass moisture content, biomass particle size, pelleting pressure, and ultrasonic power) on power consumption are investigated. Results show that power consumption in UV-A pelleting increases as moisture content and particle size decrease, and as pelleting pressure and ultrasonic power increase.

Keywords: biofuel, biomass, pelleting, power consumption, ultrasonic

\section{Introduction}

Liquid transportation fuels (including gasoline, diesel, and jet fuels) account for 70\% of the U.S. petroleum consumption [1]. In 2010, the U.S. transportation sector consumed about 19 million barrels of petroleum every day, and about half of them were imported [2]. Use of petroleum-based liquid transportation fuels contributes to the accumulation of GHG (greenhouse gas) in the atmosphere. These conditions plus other concerns (finite reserves, non-uniform distribution, and volatile price of petroleum) make it critically important to develop domestic sustainable alternatives to petroleum-based liquid transportation fuels $[3,4]$. 
One such alternative is cellulosic ethanol made from cellulosic biomass (herbaceous, woody, and generally inedible portions of plant matter). Cellulosic biomass is abundant and relatively inexpensive. Land resources in the U.S. are sufficient to sustain production of enough cellulosic biomass (about 1.3 billion dry tons) annually to replace $30 \%$ or more of the nation's current consumption of liquid transportation fuels $[5,6]$. Cellulosic ethanol reduces GHG emissions by $85 \%$ over petroleum-based fuels [5,6]. In addition, a cellulosic ethanol industry would create jobs, increase farmers' income, and boost rural economy [6].

Figure 1 shows major steps in manufacturing of cellulosic ethanol. A major challenge to cellulosic biofuel manufacturing is the high costs in storage, transportation, and handling of low density biomass. Pelleting of cellulosic biomass can significantly increase the density of cellulosic biomass and reduce the costs in biomass storage, transportation, and handling [9].

Traditional pelleting methods (e.g., using a screw extruder, a briquetting press, or a rolling machine $[10,11])$ usually involve high-temperature steam, high pressure, and binder materials. It is difficult to realize cost-effective pelleting at or near the fields where cellulosic biomass is available by using traditional pelleting methods. Ultrasonic vibration-assisted (UV-A) pelleting, without using high-temperature steam and binder materials, can produce pellets whose density is comparable to those produced by using traditional pelleting methods [12].

The literature on UV-A pelleting is focused on experimental investigations on pellet quality (density, durability, and stability) and sugar yield. However, power consumption in UV-A pelleting has not been fully investigated. The objective of this paper is to 
investigate the effects of input variables on power consumption in UV-A pelleting. The input variables include biomass moisture content, biomass particle size, pelleting pressure, and ultrasonic power.

\section{Materials and methods}

\subsection{Raw biomass material}

The pelleting feedstock used in this study was wheat straw harvested in northwestern Kansas in July of 2010. The wheat straw had been run through a John Deere 9600 combine (that removed wheat grains from wheat straw and chaff) and collected. The collected wheat straw had an average length of $25 \mathrm{~cm}$. After harvesting and collection, wheat straw was stored in bags before use.

\subsection{Size reduction}

The size of wheat straw was further reduced using a hammer mill (model 35, Meadows Mills, Inc., North Wilkesboro, NC, USA), as shown in Figure 2. The hammer mill used a 240-volt, 5-horsepower electric motor. The hammer mill had a steel drum containing a rotating shaft on which 24 hammers were mounted. The rotation speed of shaft was fixed at $3600 \mathrm{rpm}$ and the hammers were free to swing. The size of hammers was $101.6 \times 25.4 \times 4.8 \mathrm{~mm}$. The wheat straw was fed into the grinding drum from the top of the hammer mill. The rotating hammers impacted the wheat straw to reduce the size of wheat straw. The produced particles would pass through the sieve at the bottom of the grinding chamber when they were small enough [13]. The screen size of the sieve in the hammer mill was $2 \mathrm{~mm}$. 


\subsection{Separation of particle sizes}

Wheat straw particles from hammer milling had a wide size distribution. The particles were then separated into different size ranges using a sieve shaker (model RX-29, W.S. Tyler, Inc., Mentor, OH, U.S.), as shown in Figure 3. A series of sieves with different screen sizes were loaded on an agitation tray. Particles were put on the top sieve that had the largest screen size. A hammer stroke a cover located above the sieves at the rate of three times per second. Meanwhile, the agitation tray moved circularly at 200 rpm. The running time of the sieve shaker was 10 minutes.

Particle sizes were determined by the screen size of the sieves. Table 1 lists the screen sizes of the six sieves used to separate the wheat straw particles. Theoretically, particles should be separated into seven different size ranges with these six sieves. However, almost all particles fell through the $2.4 \mathrm{~mm}$ sieve, so the particle size range of $>2.4 \mathrm{~mm}$ was excluded. Therefore, particles were separated into six different size ranges: $<0.2,0.2-0.3,0.3-0.4,0.4-0.6,0.6-1.2$, and $1.2-2.4 \mathrm{~mm}$. These six particle size ranges were investigated in this study.

\subsection{Adjustment of biomass moisture content}

Biomass moisture content represents the amount of moisture (water) contained in a certain amount of biomass (wheat straw in this study). The initial moisture content was determined by drying about $25 \mathrm{~g}$ of wheat straw particles (after hammer milling) in an oven (Blue M Electric Co., Blue island, IL, USA) at $103^{\circ} \mathrm{C}$ for 24 hours according to ASABE standard S358.2 [14]. After drying, the dried particles were weighed by using an electronic scale (Ohaus, Pine Brook, NJ, USA). The initial moisture content was 
calculated as the ratio of the loss in weight during drying to the weight of pre-dried sample. In this study, the initial moisture content was determined as 5\%.

Another four levels of moisture content were also investigated in this study: $10 \%$, $15 \%, 20 \%$, and $25 \%$. The initial moisture content was adjusted to the higher levels by adding distilled water based on the ASABE standard [14]. Then, the wheat straw particles were stored in zip-lock bags until being pelleted.

\subsection{UV-A pelleting}

Pelleting was performed on a modified ultrasonic machine (model AP-1000, SonicMill, Albuquerque, NM, U.S.). Fig. 4 is a schematic illustration of the experimental set-up for UV-A pelleting. The machine included a power supply (which converts $60 \mathrm{~Hz}$ electrical power into $20,000 \mathrm{~Hz}$ electrical power), a converter (which converts high frequency electrical energy into vibration), and a titanium tool (which was connected to converter). The tip of the tool was a solid cylinder (17.4 $\mathrm{mm}$ in diameter) with a flat end. The vibration frequency of the tool was fixed at $20 \mathrm{kHz}$.

The pneumatic cylinder was driven by compressed air provided by a $1.6 \mathrm{HP}, 33$ gallon air compressor (Sears, Roebuck and Co., Hoffman Estates, IL, U.S.). The pelleting pressure represented air pressure in the pneumatic cylinder. The air pressure was controlled by a pressure regulator. A higher air pressure in the cylinder would cause a higher pressure applied on the wheat straw particles in the mold by the tool.

Ultrasonic power was referred to the power provided by the power supply. It controlled the amplitude of the tool vibration. A larger ultrasonic power would result in larger vibration amplitude. Ultrasonic power was expressed as a percentage of the maximum ultrasonic power for the power supply. It could be adjusted from 0 (no 
ultrasonic power) to $100 \%$ (the maximum ultrasonic power).

An aluminum mold made in three parts that were assembled together with pins was used in UV-A pelleting. The upper two parts formed a cylindrical cavity $(18.6 \mathrm{~mm}$ in diameter). The bottom part served as a base. There are six steps to make a pellet in UV-A pelleting: (1) one gram of wheat straw particles was loaded into the center cavity of the mold and the mold was clamped by a fixture, (2) the pelleting tool was fed down to compress the wheat straw particles in the mold, (3) turn on ultrasonic power and apply ultrasonic vibration to the tool, (4) record pelleting time, (5) turn off ultrasonic power and retract the tool, and (6) disassemble the mold and unload the cylindershaped pellet. Table 2 shows experimental parameters and their values. Ten replicates were made under each experimental condition.

\subsection{Measurement of power consumption}

The term "power consumption" in this paper refers to the electricity consumed by the ultrasonic power supply. It measured the power consumed to produce pellets with a specific density (around $930 \mathrm{~kg} / \mathrm{m}^{3}$ ). Different pelleting time was needed to produce the specific density under different conditions. In this study, the pelleting time for each condition was determined (to produce $930-\mathrm{kg} / \mathrm{m}^{3}$ density) based on a regression model developed by Fan et al. [15] to predict pellet density in UV-A pelleting under different conditions. In each measurement of power consumption, the pelleting time and pellet density were recorded.

Power consumption was measured by a power analyzer (AEMC 2010.86 PowerPad Jr. Model 8230, AEMC-Instruments, Foxborough, MA). Voltage probe leads were connected to the 120 Volt $A C$ cable and a current sensor was clamped around the AC 
cable. The power analyzer began recording voltage and current when the tool started dropping and stopped recording data when the tool started retreating.

\subsection{Measurement of pellet density}

Pellet density means the density of an individual pellet and was determined by ratio of its weight to its volume. Weight of the pellet was measured by an electronic scale (Ohaus, Pine Brook, NJ, U.S.). The volume of a pellet was determined by its diameter and height measured with a vernier caliper.

\section{Results and discussion}

\subsection{Effects of moisture content}

The effects of moisture content on power consumption are shown in Table 3 and Figure 5. The error bars in Figure 5 represent the standard deviations presented in Table 3. The pellet densities at different levels of moisture content are presented in Figure 5 (a). Statistic tests were conducted to compare the densities. The results showed that there was no significant difference between the densities at the significance level of 0.05 .

Different pelleting time was needed to produce the same pellet density at different levels of moisture content when other input variables were kept the same. As shown in Figure 5 (b), pelleting time increased slightly as moisture content increased from $5 \%$ to $15 \%$. Much longer pelleting time was needed when moisture content was $15 \%$ and $25 \%$. This indicates that higher moisture content would lead to lower pellet density if same pelleting time was used. This was consistent with the results of earlier studies. 
Song et al. [16] reported that, with the same pelleting time, lower moisture content (13\%) produced wheat straw pellets with higher density than higher moisture content (20\% and 25\%) in UV-A pelleting. Similar results were also reported by Zhang et al. [17].

As shown in Figure 5 (c), power consumption in UV-A pelleting increased slightly as moisture content increased from $5 \%$ to $15 \%$. As moisture content increased from $15 \%$ to $25 \%$, power consumption had a dramatic increase. This trend is very similar to that between moisture content and pelleting time. When moisture content was 5\%, 10\%, and $15 \%$, both pelleting time and power consumption slightly increased. When moisture content was $20 \%$ and $25 \%$, both pelleting time and power consumption increased dramatically. There was an obvious correlation between pelleting time and power consumption. This indicates that the higher power consumption for higher moisture content was at least partially caused by longer pelleting time.

Power consumption rate for different levels of moisture content is presented in Figure 5 (d). When moisture content increased to $20 \%$ or $25 \%$, power consumption rate was much higher than those when moisture content was lower. This indicates that, excluding the effects of pelleting time, higher moisture content in itself would lead to higher power consumption. Therefore, from the viewpoint of power consumption, the moisture content of wheat straw particles in UV-A pelleting should be lower than $15 \%$.

Earlier studies also showed that higher moisture content (higher than 15\%) in UV-A pelleting led to lower pellet durability and stability [17]. Therefore, lower moisture content is preferable in UV-A pelleting. 
Similar relations between moisture content and pellet quality (such as density, durability, and stability) were reported in the literature by using other pelleting methods and other biomass materials. Fasina and Sokhansanj [18] reported effects of moisture content on pellet durability. When pelleting of alfalfa, as moisture content increased, durability increased first before reaching a maximum value of about $86 \%$ when moisture content was 5\%, and then decreased. Fasina [19] studied the effects of moisture content on durability of peanut hull pellets. As moisture content increased, pellet durability increased first and reached a maximum value of $90 \%$ when moisture content was $9 \%$, and then decreased. An increase in moisture content also resulted in decrease in pellet density. Colley et al. [20] studied the effects of moisture content on switchgrass pellets. As moisture content increased, pellet density decreased. Mani et al. [21] reported that moisture content significantly affected pellet density of barley straw, corn stover, and switchgrass using a single pellet unit (piston press pelleting).

\subsection{Effects of particle size}

The effects of particle size on power consumption are shown in Table 4 and Figure 6. The error bars in Figure 6 represent the standard deviations presented in Table 4. The pellet densities at different levels of particle size are presented in Figure 6 (a). There was no significant difference between the densities at the significance level of 0.05 .

As shown in Figure 6 (b), pelleting time increased as particle size increased. This indicates that larger particle size would lead to lower pellet density if same pelleting time was used. This trend was consistent with earlier results on relations between sieve size and pellet density. Zhang et al. [12] reported that, with the same pelleting time, smaller 
sieve size $(0.25 \mathrm{~mm})$ produced higher density for wheat straw pellets than larger sieve size $(8 \mathrm{~mm})$ in UV-A pelleting. Zhang et al. [22] studied pellet density in UV-A of wheat straw particles using a $2^{4}$ full factorial design with two levels of sieve size ( 1 and $2 \mathrm{~mm}$ ). They reported that wheat straw particles milled with the smaller sieve size produced much higher pellet density than those milled with the larger sieve size. Similar results were reported by Mani et al. [21] who studied effects of particle size on pellet density of barley straw, corn stover, and switchgrass using a single pellet unit. When particle size decreased from $3.2 \mathrm{~mm}$ to $0.8 \mathrm{~mm}$, the pellet density increased linearly.

The effects of particle size on power consumption are shown in Figure 6 (c). It is obvious that power consumption increased as particle size decreased. This result is consistent with a previous study in which effects of particle size (3.2 and $9.6 \mathrm{~mm}$ ) on pelleting power consumption of corn stover, sorghum stalk, big blue, and wheat straw were investigated by using two pelleting methods [23]. One was ring-die pelleting (a traditional pelleting method) and the other was UV-A pelleting. It is reported that $3.2 \mathrm{~mm}$ particles consumed less power than $9.6 \mathrm{~mm}$ particles in both pelleting methods. It can be seen from Figure 6 (c) that the trend between particle size and power consumption is similar to that between particle size and pelleting time. The correlation between pelleting time and power consumption indicates that higher power consumption of smaller particle size might be caused by longer pelleting time.

Power consumption rate for different particle size is presented in Figure 6 (d). As particle size increased, power consumption rate decreased. This indicates that the higher power consumption for larger particle size was totally caused by the longer pelleting time needed to produce the specific pellet density. Therefore, from the 
viewpoint of energy consumption in UV-A pelleting, smaller particle size was preferable to producing pellets with a specific density.

Earlier studies on UV-A pelleting showed that smaller particles were also preferable to produce pellets with high durability and stability $[12,22]$. However, inconsistent relations between particle size and pellet quality were reported by other studies in which other pelleting methods were used. Theerarattananoon et al. [24] reported that sieve size of hammer mill did not have significant effects on pellet density and durability in ring-die pelleting. Similar results were also reported by Tabil and Sokhansanj [25].

Some researchers believed that smaller particle size increased the surface area of biomass [26]. The increase in surface area of biomass allowed easier access by enzymes, resulting in higher sugar yield in hydrolysis. However, Zhang et al. [27] reported that particle size in the range of $0.2-2.4 \mathrm{~mm}$ of switchgrass did not have significant effects on sugar yield in hydrolysis after UV-A pelleting. This result might be due to the narrow ranges of particle sizes.

Smaller particle sizes required more power in size reduction [28]. Deines and Pei [29] reported that more power was consumed to produce smaller particle size in knife milling of switchgrass.

\subsection{Effects of pressure}

The effects of pelleting pressure on power consumption are shown in Table 5 and Figure 7. The error bars in Figure 7 represent the standard deviations presented in Table 5. The pellet densities of different pressure are presented in Figure 7 (a). There was no significant difference between the densities at the significance level of 0.05 .

As shown in Figure 7 (b), pelleting time decreased as pressure increased. This 
indicates that lower pressure would lead to lower pellet density if same pelleting time was used. This trend was consistent with earlier results. Zhang et al. [30] investigated four levels of pelleting pressure $(138,206,275$, and $344 \mathrm{kPa})$ in UV-A pelleting. A significant increase in pellet density was found as pressure increased from 138 to 344 $\mathrm{kPa}$. Similar trend was also reported by Zhang et al. [22].

The effects of pressure on power consumption are shown in Figure 7 (c). It is obvious that power consumption decreased as pressure increased. The relations between power consumption rate and pressure are presented in Figure 7 (d). As pressure increased, there was no significant change in power consumption rate. This indicates that the higher power consumption for lower pressure was totally caused by the longer pelleting time needed to produce the specific pellet density. Therefore, from the viewpoint of energy consumption and productivity in UV-A pelleting, higher pressure was preferable.

Previous studies also showed that as pressure increased from 138 to $275 \mathrm{kPa}$, pellet durability increased [30]. As pressure increased from 138 to $275 \mathrm{kPa}$, there was no significant change in pellet stability [30].

\subsection{Effects of ultrasonic power}

The effects of ultrasonic power on power consumption are shown in Table 6 and Figure 8. The error bars in Figure 8 represent the standard deviations presented in Table 6. The pellet densities for different levels of ultrasonic power are presented in Figure 8 (a). There was no significant difference between the densities at the significance level of 0.05 .

As shown in Figure 8 (b), pelleting time decreased rapidly as ultrasonic power 
increased. This indicates that lower ultrasonic power would lead to lower pellet density if same pelleting time was used. This trend was consistent with earlier results. Zhang et al. [30] investigated four levels of ultrasonic power $(30 \%, 40 \%, 50 \%$, and $55 \%)$ in UV-A pelleting. A significant increase in pellet density was found as ultrasonic power increased from $30 \%$ to $55 \%$. Similar trend was also reported in the results of a test with a $2^{4}$ factorial design [22].

The effects of pressure on power consumption are shown in Figure 8 (c). Power consumption decreased rapidly as ultrasonic power increased from $50 \%$ to $100 \%$. The effects of ultrasonic power on power consumption rate are presented in Figure 8 (d). As ultrasonic power increased, power consumption rate increased. This indicates that the higher power consumption for lower ultrasonic power was totally caused by the longer pelleting time needed to produce the specific pellet density. Therefore, from the viewpoint of energy consumption in UV-A pelleting, higher ultrasonic power was preferable.

Higher ultrasonic power could produce pellets with higher durability and stability [30]. Sugar yield in hydrolysis also increased as ultrasonic power in UV-A pelleting increased [30]. Overall, using higher ultrasonic power was beneficial to UV-A pelleting.

\section{Conclusions}

This paper presents the effects of moisture content, particle size, pressure, and ultrasonic power on power consumption in ultrasonic vibration-assisted (UV-A) pelleting. The following conclusions can be drawn from the study.

(1) As moisture content increased from $5 \%$ to $15 \%$, power consumption in UV-A pelleting did not change much. As moisture content increased from $15 \%$ to $25 \%$, 
power consumption increased dramatically. Excluding the effects of pelleting time, higher moisture content in itself would lead to higher power consumption. Lower moisture content is preferable in UV-A pelleting.

(2) As particle size increased, power consumption in UV-A pelleting increased but power consumption rate decreased. The higher power consumption for larger particle size was totally caused by the longer pelleting time needed to produce the specific pellet density. Smaller particle size is beneficial to UV-A pelleting in terms of high pellet quality and low power consumption. However, the power consumption in size reduction is increased dramatically to produce smaller particles.

(3) As pressure increased from 206 to $344 \mathrm{kPa}$, power consumption in UV-A pelleting decreased but there was no significant change in power consumption rate. The higher power consumption for lower pressure was totally caused by the longer pelleting time needed to produce the specific pellet density.

(4) As ultrasonic power increased from $50 \%$ to $100 \%$, power consumption in UV-A pelleting decreased but power consumption rate increased. The higher power consumption for lower ultrasonic power was totally caused by the longer pelleting time needed to produce the specific pellet density.

\section{Acknowledgements}

This work was supported by NSF through Award No. CMMI-0970112. The authors gratefully extend their acknowledgements to Graham Pritchett and Levi Riley at Kansas State University for their help in conducting experiments, and Mr. Clyde Treadwell at Sonic Mill for his technical support on experimental equipment. 


\section{References}

[1] Institute for Energy Research, 2010, Petroleum, retrieved from: http://www.instituteforenergyresearch.org/energy-overview/petroleum-oil/.

[2] Energy Information Administration, 2011, Short-term energy outlook, retrieved from: http://www.eia.doe.gov/emeu/states/sep_sum/html/sum_btu_tra.html.

[3] G.W. Huber, 2008, Breaking the chemical and engineering barriers to lignocellulosic biofuels: next generation hydrocarbon biorefineries, retrieved from: http://www.ecs.umass.edu/biofuels/Images/Roadmap2-08.pdf.

[4] L.R. Lynd, J.H. Cushman, R.J. Nichols, C.E. Wyman, J. Fuel, Ethanol from cellulosic biomass, Science 25 (1991) 1318-1323.

[5] R.D. Perlack, L.L. Wright, A.F. Turhollow, R.L. Graham, B.J. Stokes, D.C. Erbach, Biomass as feedstocks for a bioenergy and byproducts industry: the technical feasibility of a billion-ton annual supply, DOE Technical Paper No. GO-1020052135, 2005.

[6] U.S. Department of Energy, 2009, Breaking the biological barriers to cellulosic ethanol: a joint research agenda, retrieved from: http:// genomicscience.energy.gov/biofuels/b2bworkshop.shtml.

[7] J. Moresco, 2008, US biofuel output to miss mandates, retrieved from: http://www.redherring.com/Home/25682.

[8] E.M. Rubin, Genomics of cellulosic biofuels, Nature 454 (2008) 841-845.

[9] R.H. Leaver, The Pelleting Process, Sprout-Waldron, Muncy, PA, USA, 1984.

[10] A.K. Tripathi, P. Lyer, T.C. Kandpal, A techno-economic evaluation of biomass briquetting in India, Biomass Bioenerg. 14 (1998) 479-488. 
[11] S. Sokhansanj, S. Mani, P. Zaini, Binderless pelletization of biomass, ASABE Paper No. 056061, 2005.

[12] Q. Zhang, P.F. Zhang, T. Deines, M. Zhang, X.X. Song, Z.J. Pei, Ultrasonic vibration assisted pelleting of wheat straw: effects of particle size, Proc. FAIM, July 12-14, 2010, California State University, CA, USA.

[13] L. Austin, A preliminary simulation model for fine grinding in high speed hammer mills, Powder Technol. 143 (2004) 240-252.

[14] ASABE Standard S358.2, Moisture measurement-forge, American Society of Agricultural and Biological Engineers, St. Joseph, MI, USA, 1998.

[15] K.Q. Fan, P.F. Zhang, Z.J. Pei, Ultrasonic vibration-assisted pelleting of wheat straw: a predictive model for pellet density using response surface methodology, Biofuels. 3 (2012) 259-267.

[16] X.X. Song, M. Zhang, Z.J. Pei, T.W. Deines, Ultrasonic-vibration-assisted pelleting of cellulosic biomass: effects of moisture content, Proc. MSEC, October 12-15, 2010, Erie, PA, USA.

[17] P.F. Zhang, T. Deines, W.L. Cong, N. Qin, Z.J. Pei, D. Nottingham, Ultrasonic vibration-assisted pelleting of switchgrass: effects of moisture content on pellet density, spring-back, and durability, Proc. FAIM, July 12-14, 2010, California State University, CA, USA.

[18] O.O. Fasina, S. Sokhansanj, Storage and handling characteristics of alfalfa pellets, J. Powder Handl. Process 8 (1996) 361-365.

[19] O.O. Fasina, Physical properties of peanut hull pellets, Bioresour. Technol. Vol. 99 (2008) 1259-1266. 
[20] Z. Colley, O.O. Fasina, D. Bransby, Y.Y. Lee, Moisture effect on the physical characteristics of switchgrass pellets, Trans. ASABE 49 (2006) 1845-1851.

[21] S. Mani, L. G. Tabil, S. Sokhansanj, Effect of compressive force, particle size and moisture content on mechanical properties of biomass pellets from grasses, Biomass Bioenerg. 30 (2006) 648-654.

[22] P.F. Zhang, T.W. Deines, D. Nottingham, Z.J.Pei, D. Wang, X.R. Wu, Ultrasonicvibration-assisted pelleting of biomass: A designed experimental investigation on pellet quality and sugar yield, Proc. MSEC, October 12-15, 2010, Erie, PA, USA.

[23] Q. Zhang, P.F. Zhang, Z.J. Pei, J. Wilson, L. McKinney, G. Pritchett, Ultrasonicvibration assisted pelleting for cellulosic ethanol manufacturing: an experimental investigation of power consumption, Proc. IMECE, November 11-17, 2011, Denver, Colorado, USA.

[24] K. Theerarattananoon, F. Xu, J. Wilson, R. Ballard, L. Mckinney, S. staggenborg, P, Vadlani, Z.J. Pei, D. Wang, Physical properties of pellets made from sorghum stalk, corn stover, wheat straw and big bluestem, Ind. Crops Prod. 33 (2011) 325332.

[25] L.G. Tabil, S. Sokhansani, Compression and compaction behavior of alfalfa grinds part 1- compression behavior, J. Power Handl. Process. 8 (1996) pp.17-23.

[26] M. Zeng, N.S. Mosier, C.P. Huang, D.M. Sherman, M.R. Ladisch, Microscopic examination of changes of plant cell structure in corn stover due to hot water pretreatment and enzymatic hydrolysis, Biotechnol. Bioeng. 97 (2007) 265-278. 
[27] P.F. Zhang, Q. Zhang, Z.J. Pei, L. Pei, Ultrasonic vibration-assisted pelleting in manufacturing of cellulosic biofuels: effects of particle size on sugar yield, Proc. IMECE, November 11-17, 2011, Denver, Colorado, USA.

[28] S. Mani, L.G. Tabil, S. Sokhansanj, Grinding performance and physical properties of wheat and barley straw, corn stover and switchgrass, Biomass Bioenerg. 27 (2004) 339-352.

[29] T.W. Deines, Z.J. Pei, Power consumption study in knife milling of wheat straw, Trans. NAMRI 38 (2011) 191-196.

[30] Q. Zhang, P.F. Zhang, T.W. Deines, Z.J. Pei, D.H. Wang, X.R. Wu, G. Pritchett, Ultrasonic vibration assisted pelleting of sorghum: effects of pressure and ultrasonic power, Proc. IMECE, October 12-15, 2010, Erie, PA, USA. 


\section{List of figures}

Figure 1_Major steps in biofuel manufacturing

Figure 2_Size reduction by a hammer mill

Figure 3_Sieve shaker

Figure 4_Illustration of UV-A pelleting

Figure 5_Results for different levels of moisture content

Figure 6_Results for different levels of particle size

Figure 7_Results for different levels of pressure

Figure 8_Results for different levels of ultrasonic power 


\section{List of Tables}

Table 1_Screen sizes of sieves

Table 2_Experimental parameters and values

Table 3_Results for different levels of moisture content

Table 4_Results for different levels of particle size

Table 5_Results for different levels of pelleting pressure

Table 6_Results for different levels of ultrasonic power 


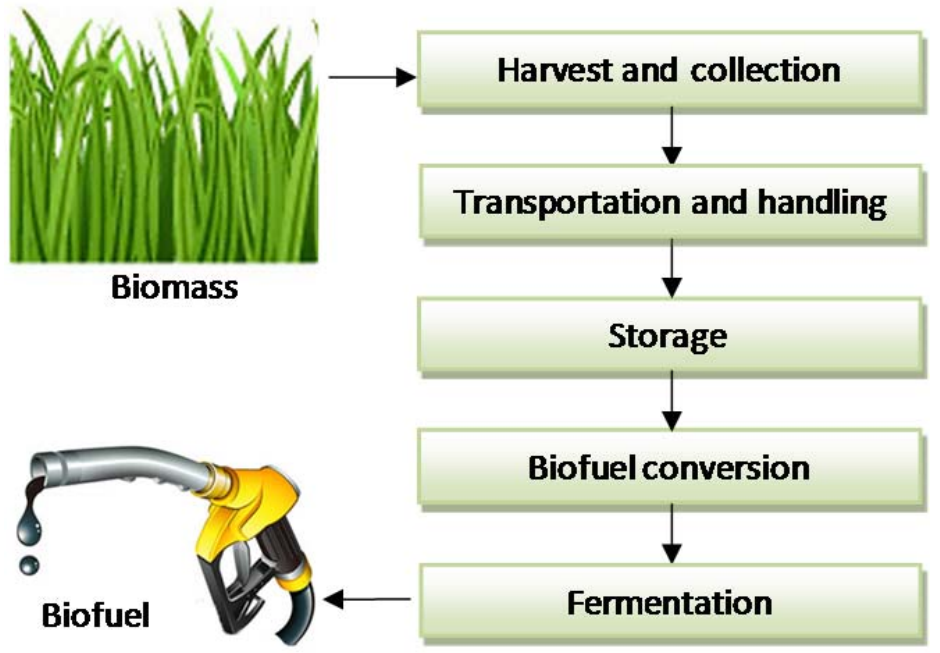

Figure 1 Major steps in biofuel manufacturing (after $[7,8]$ ) 


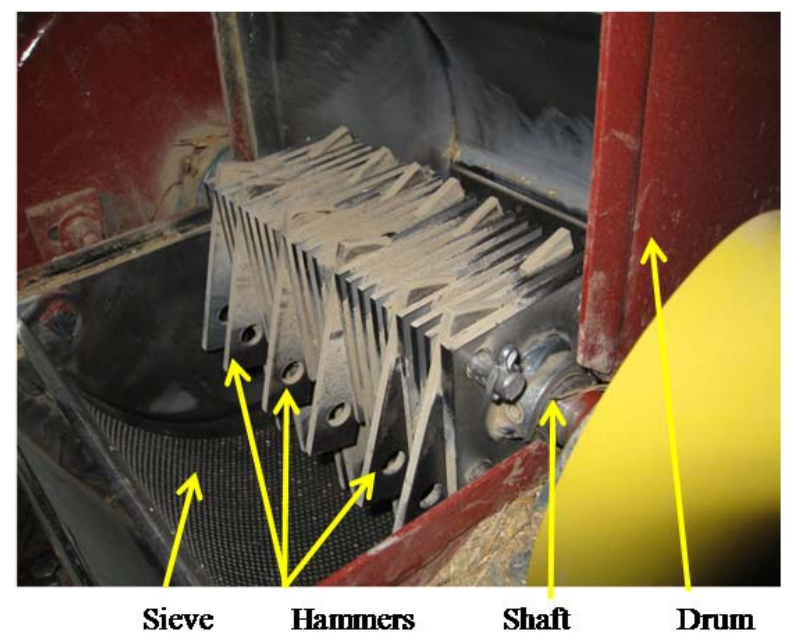

Figure 2 Size reduction by a hammer mill 


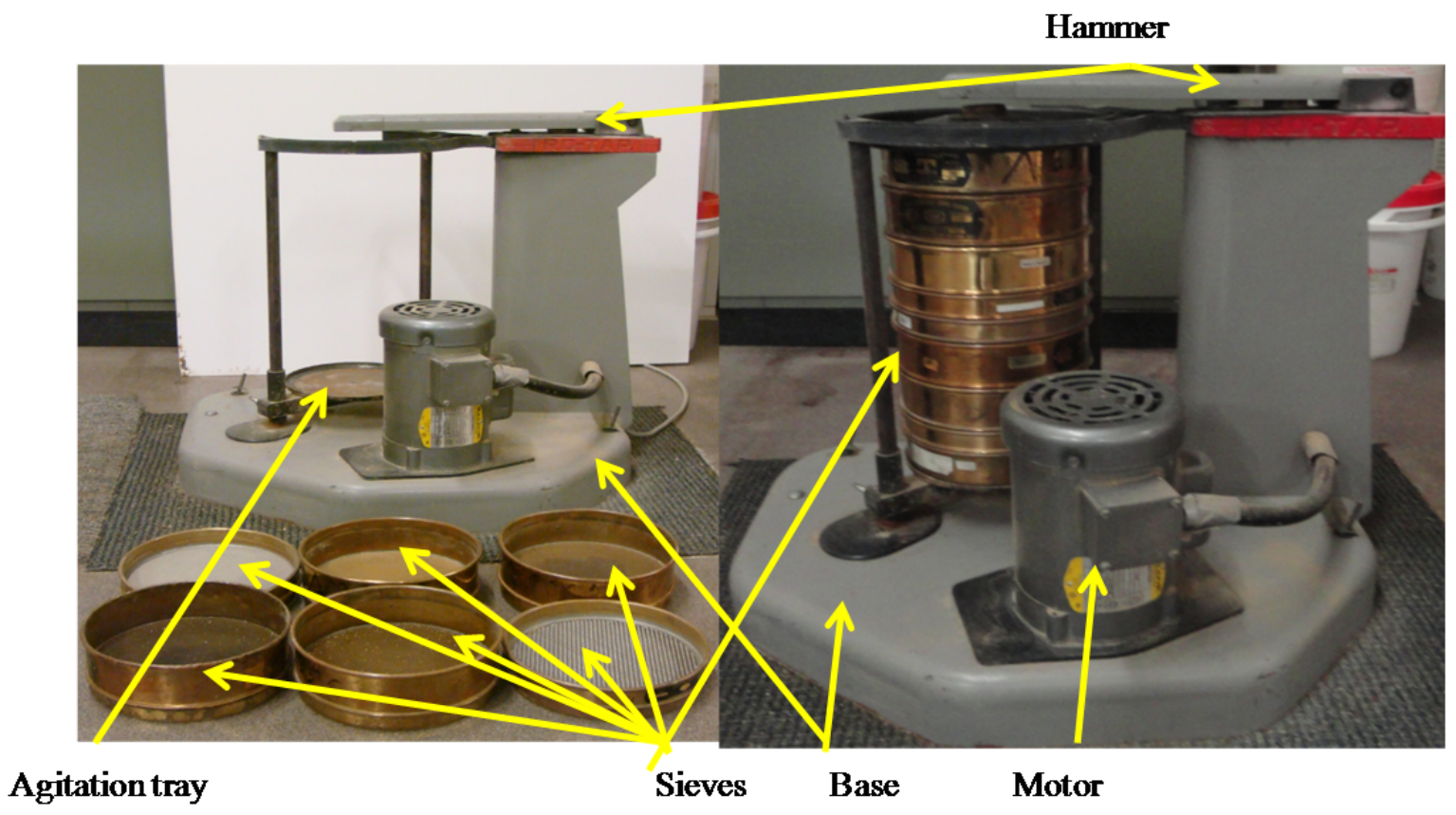

Figure 3 Sieve shaker 


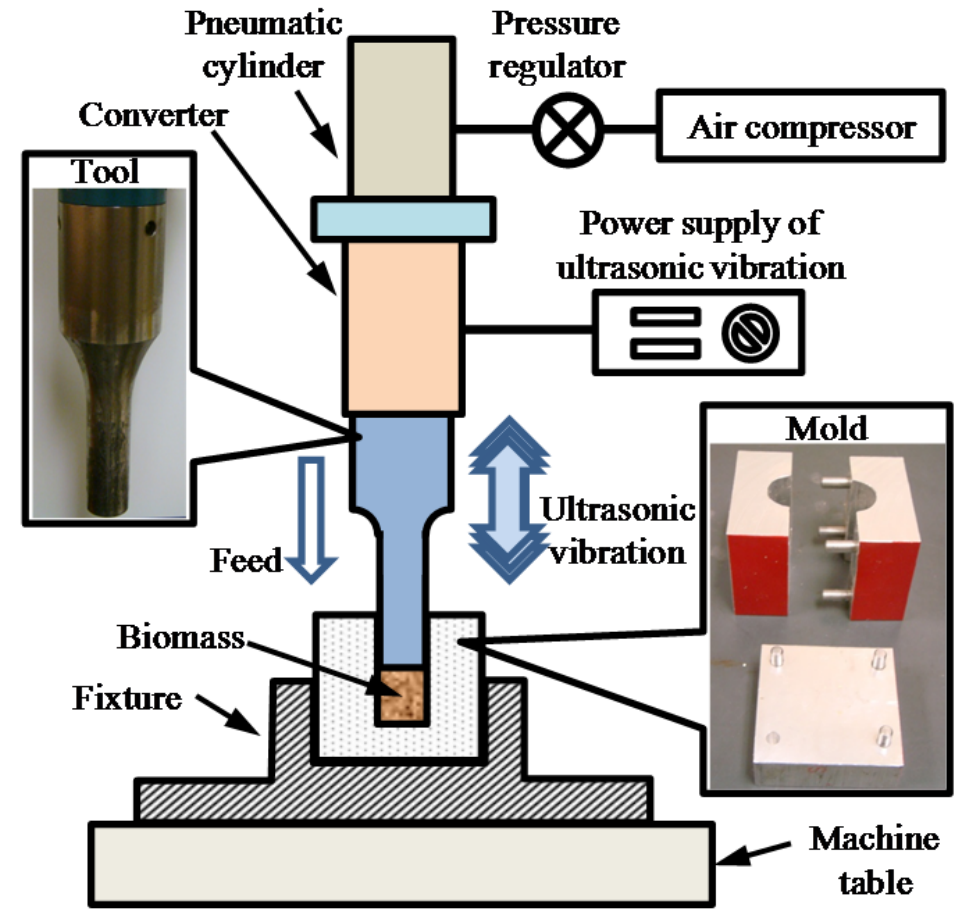

Figure 4 Illustration of UV-A pelleting 

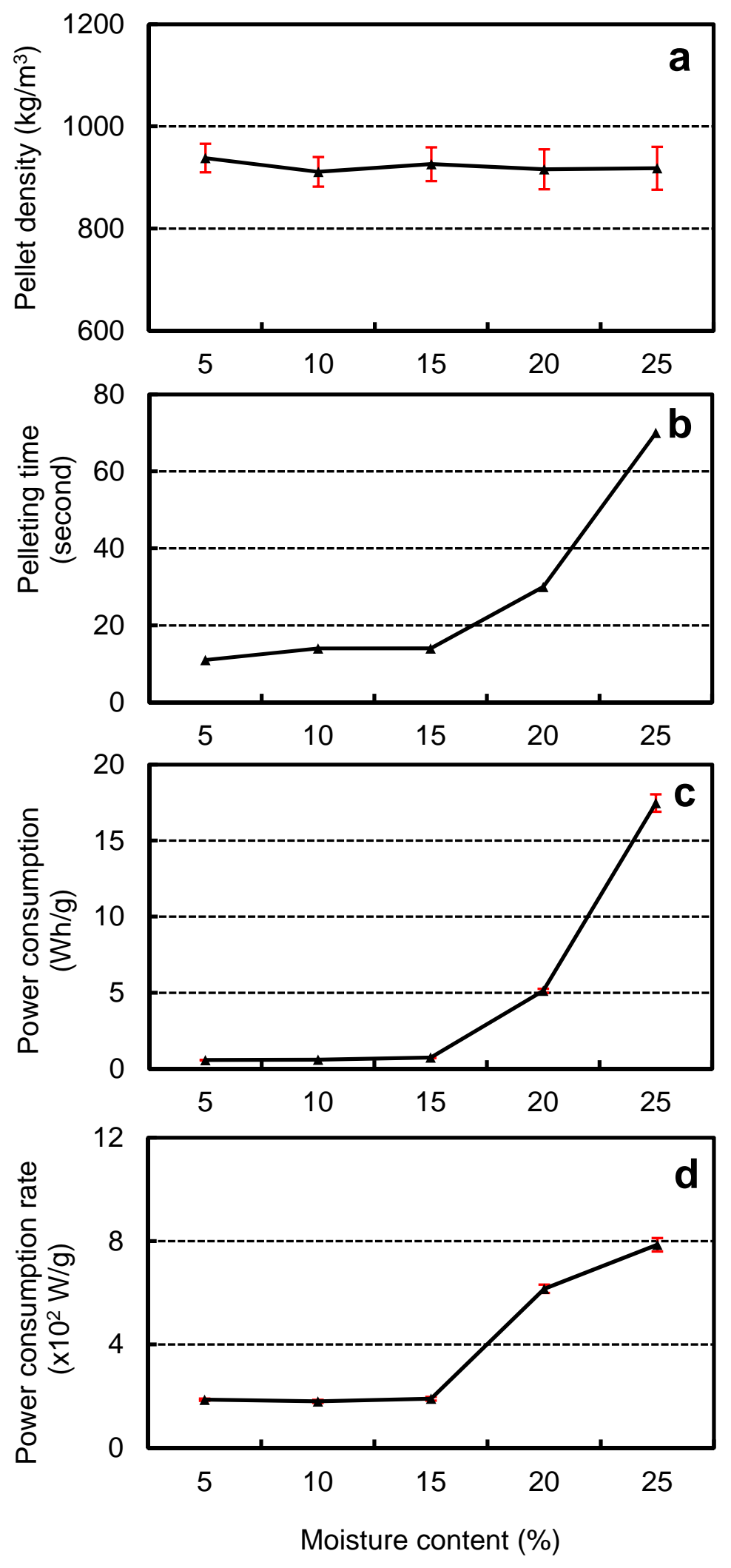

Figure 5 Results for different levels of moisture content 

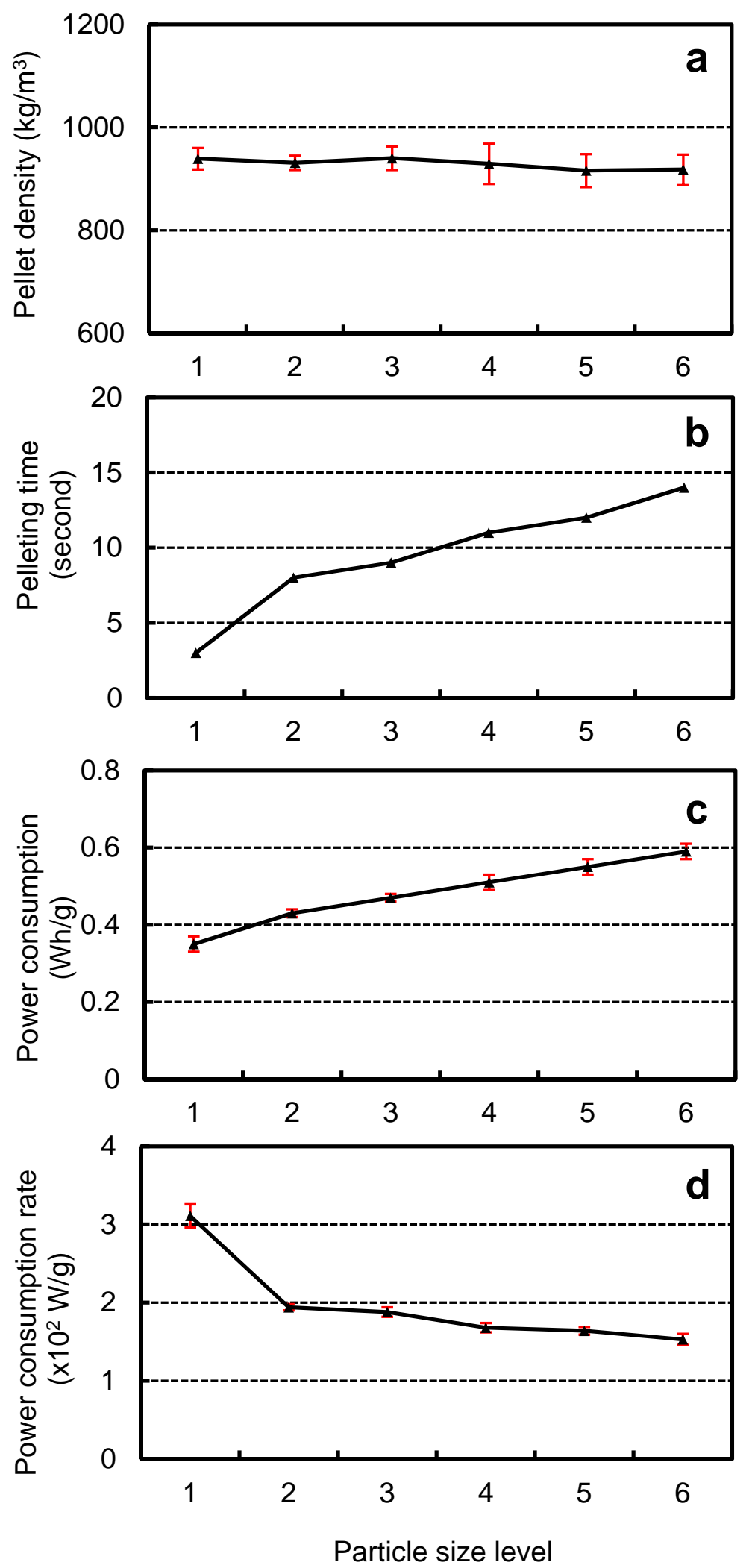

Figure 6 Results for different levels of particle size (particle size level 1 - 6 refers to particle size ranges of $<0.2,0.2-0.3,0.3-0.4,0.4-0.6,0.6-1.2$, and $1.2-2.4 \mathrm{~mm}$ respectively) 

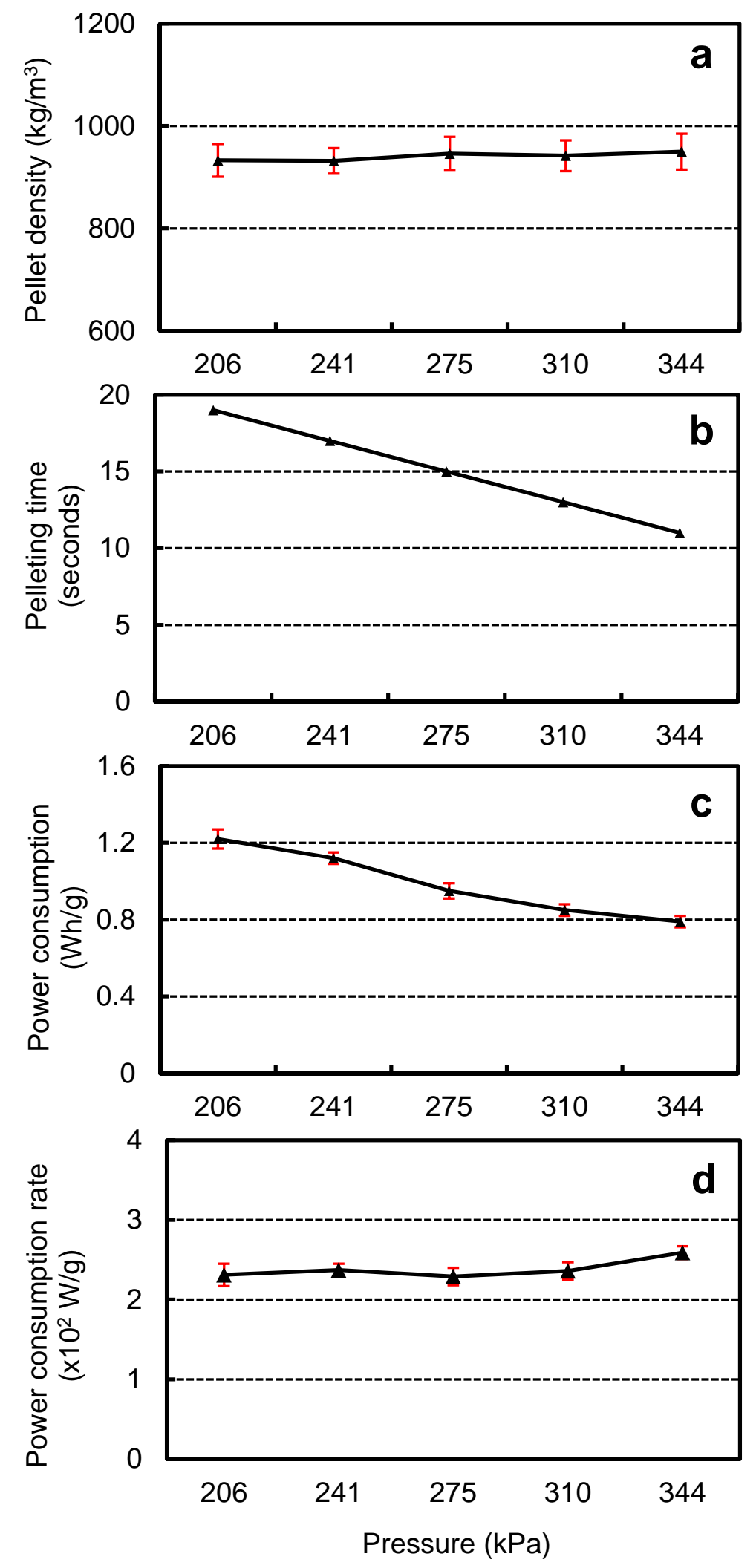

Figure 7 Results for different levels of pressure 

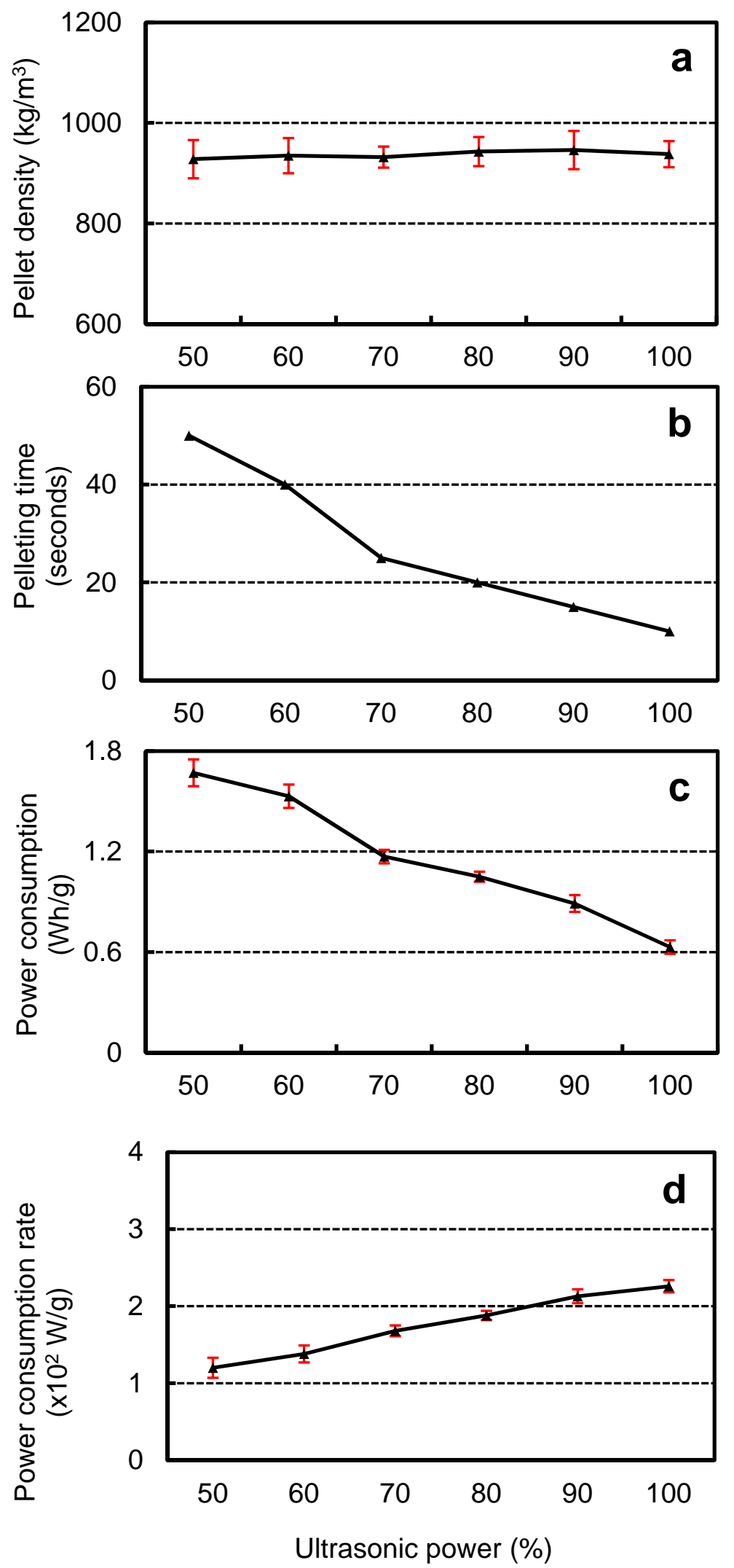

Figure 8 Results for different levels of ultrasonic power 
Table 1 Screen sizes of sieves

\begin{tabular}{cc}
\hline Sieve \# & $\begin{array}{c}\text { Screen Size } \\
(\mathrm{mm})\end{array}$ \\
\hline \hline 1 & 2.4 \\
2 & 1.2 \\
3 & 0.6 \\
4 & 0.4 \\
5 & 0.3 \\
6 & 0.2 \\
\hline
\end{tabular}


Table 2 Experimental parameters and values

\begin{tabular}{|c|c|c|c|}
\hline $\mathrm{MC}(\%)$ & Particle size (mm) & Pressure $(\mathrm{kPa})$ & Ultrasonic power (\%) \\
\hline 10 & $\begin{array}{c}<0.2 ; 0.2-0.3 ; 0.3- \\
0.4 ; 0.4-0.6 ; 0.6-1.2 ; \\
1.2-2.4\end{array}$ & 344 & 95 \\
\hline $5 ; 10 ; 15 ; 20 ; 25$ & $2^{*}$ & 344 & 95 \\
\hline 10 & $2^{*}$ & $206 ; 241 ; 275 ; 310 ; 344$ & 95 \\
\hline 10 & $2^{*}$ & 344 & $50 ; 60 ; 70 ; 80 ; 90 ; 100$ \\
\hline
\end{tabular}

*Particles were obtained from hammer milling with $2 \mathrm{~mm}$ sieve size. 
Table 3 Results for different levels of moisture content

\begin{tabular}{ccccc}
\hline $\begin{array}{c}\text { Moisture content } \\
(\%)\end{array}$ & $\begin{array}{c}\text { Density* } \\
\left(\mathrm{kg} / \mathrm{m}^{3}\right)\end{array}$ & $\begin{array}{c}\text { Pelleting time } \\
(\text { second })\end{array}$ & $\begin{array}{c}\text { Power consumption* } \\
(\mathrm{Wh} / \mathrm{g})\end{array}$ & $\begin{array}{c}\text { Power consumption rate* }^{*} \\
\left(\mathrm{x} 10^{2} \mathrm{~W} / \mathrm{g}\right)\end{array}$ \\
\hline \hline 5 & $938(28)$ & 11 & $0.57(0.01)$ & $1.86(0.04)$ \\
10 & $911(29)$ & 12 & $0.60(0.02)$ & $1.81(0.06)$ \\
15 & $926(33)$ & 14 & $0.74(0.03)$ & $1.89(0.07)$ \\
20 & $916(39)$ & 30 & $5.13(0.13)$ & $6.16(0.16)$ \\
25 & $918(42)$ & 80 & $17.47(0.57)$ & $7.86(0.26)$ \\
\hline
\end{tabular}

* Numbers outside parentheses are mean values and numbers enclosed in parentheses are standard deviations for $n=10$ 
Table 4 Results for different levels of particle size

\begin{tabular}{ccccc}
\hline $\begin{array}{c}\text { Particle size } \\
(\mathrm{mm})\end{array}$ & $\begin{array}{c}\text { Density* } \\
\left(\mathrm{kg} / \mathrm{m}^{3}\right)\end{array}$ & $\begin{array}{c}\text { Pelleting time } \\
(\text { second })\end{array}$ & $\begin{array}{c}\text { Power consumption* } \\
(\mathrm{Wh} / \mathrm{g})\end{array}$ & $\begin{array}{c}\text { Power consumption rate* }^{*} \\
\left(\times 10^{2} \mathrm{~W} / \mathrm{g}\right)\end{array}$ \\
\hline \hline$<0.2$ & $942(21)$ & 4 & $0.35(0.02)$ & $3.11(0.15)$ \\
$0.2-0.3$ & $931(14)$ & 8 & $0.43(0.01)$ & $1.94(0.04)$ \\
$0.3-0.4$ & $940(23)$ & 9 & $0.47(0.01)$ & $1.88(0.06)$ \\
$0.4-0.6$ & $929(39)$ & 11 & $0.51(0.02)$ & $1.68(0.06)$ \\
$0.6-1.2$ & $916(32)$ & 12 & $0.55(0.02)$ & $1.64(0.05)$ \\
$1.2-2.4$ & $918(29)$ & 14 & $0.59(0.02)$ & $1.53(0.07)$ \\
\hline
\end{tabular}

* Numbers outside parentheses are mean values and numbers enclosed in parentheses are standard deviations for $n=10$ 
Table 5 Results for different levels of pelleting pressure

\begin{tabular}{ccccc}
\hline $\begin{array}{c}\text { Pressure } \\
(\mathrm{kPa})\end{array}$ & $\begin{array}{c}\text { Density* } \\
\left(\mathrm{kg} / \mathrm{m}^{3}\right)\end{array}$ & $\begin{array}{c}\text { Pelleting time } \\
(\text { second })\end{array}$ & $\begin{array}{c}\text { Power consumption* } \\
(\mathrm{Wh} / \mathrm{g})\end{array}$ & $\begin{array}{c}\text { Power consumption rate* } \\
(\mathrm{W} / \mathrm{g})\end{array}$ \\
\hline \hline 206 & $933(32)$ & 19 & $1.22(0.05)$ & $2.31(0.14)$ \\
241 & $932(25)$ & 17 & $1.12(0.03)$ & $2.37(0.08)$ \\
275 & $946(33)$ & 15 & $0.95(0.04)$ & $2.29(0.11)$ \\
310 & $942(30)$ & 13 & $0.85(0.03)$ & $2.36(0.11)$ \\
344 & $950(35)$ & 11 & $0.79(0.03)$ & $2.59(0.08)$ \\
\hline
\end{tabular}

* Numbers outside parentheses are mean values and numbers enclosed in parentheses are standard deviations for $n=10$ 
Table 6 Results for different levels of ultrasonic power

\begin{tabular}{ccccc}
\hline $\begin{array}{c}\text { Ultrasonic power } \\
(\%)\end{array}$ & $\begin{array}{c}\text { Density* } \\
\left(\mathrm{kg} / \mathrm{m}^{3}\right)\end{array}$ & $\begin{array}{c}\text { Pelleting time } \\
\text { (second) }\end{array}$ & $\begin{array}{c}\text { Power consumption* } \\
(\mathrm{Wh} / \mathrm{g})\end{array}$ & $\begin{array}{c}\text { Power consumption rate* }^{*} \\
(\mathrm{~W} / \mathrm{g})\end{array}$ \\
\hline \hline 50 & $928(38)$ & 50 & $1.67(0.08)$ & $1.20(0.13)$ \\
60 & $935(35)$ & 40 & $1.53(0.07)$ & $1.38(0.11)$ \\
70 & $932(21)$ & 25 & $1.17(0.04)$ & $1.68(0.07)$ \\
80 & $943(29)$ & 20 & $1.05(0.03)$ & $1.88(0.06)$ \\
90 & $946(38)$ & 15 & $0.89(0.05)$ & $2.13(0.09)$ \\
100 & $938(26)$ & 10 & $0.63(0.04)$ & $2.26(0.08)$ \\
\hline
\end{tabular}

* Numbers outside parentheses are mean values and numbers enclosed in parentheses are standard deviations for $\mathrm{n}=10$ 